\title{
Detection of biological thiols based on a colorimetric method*
}

\author{
Yuan-yuan XU, Yang-yang SUN, Yu-juan ZHANG, Chen-he LU, Jin-feng MIAO \\ (Key Laboratory of Animal Physiology and Biochemistry, College of Veterinary Medicine, \\ Nanjing Agricultural University, Nanjing 210095, China) \\ ${ }^{\dagger}$ E-mail: mjf171647@126.com \\ Received Sept. 25, 2015; Revision accepted Feb. 16, 2016; Crosschecked Sept. 10, 2016
}

\begin{abstract}
Biological thiols (biothiols), an important kind of functional biomolecules, such as cysteine (Cys) and glutathione (GSH), play vital roles in maintaining the stability of the intracellular environment. In past decades, studies have demonstrated that metabolic disorder of biothiols is related to many serious disease processes and will lead to extreme damage in human and numerous animals. We carried out a series of experiments to detect biothiols in biosamples, including bovine plasma and cell lysates of seven different cell lines based on a simple colorimetric method. In a typical test, the color of the test solution could gradually change from blue to colorless after the addition of biothiols. Based on the color change displayed, experimental results reveal that the percentage of biothiols in the embryonic fibroblast cell line is significantly higher than those in the other six cell lines, which provides the basis for the following biothiols-related study.
\end{abstract}

Key words: Biothiols, Colorimetric detection, Bovine plasma, Cell lines http://dx.doi.org/10.1631/jzus.B1500232

CLC number: Q2-33

\section{Introduction}

Biological thiols (biothiols), an important kind of functional biomolecules, such as cysteine (Cys) and glutathione (GSH), are pivotal in many biological processes. In recent decades, many studies have demonstrated that metabolic disorder of biothiols will lead to extreme damage in human and numerous other animals (Townsend et al., 2003; Reddie and Carroll, 2008; Weerapana et al., 2010). Specifically, a low level of biothiols in vivo may cause slowed growth, liver damage, weight loss, and some other adverse influences (Wang et al., 2005; Duan et al., 2008; Yang et al., 2012), while a high level of biothiols is

\footnotetext{
${ }^{\ddagger}$ Corresponding author

* Project supported by the National Natural Science Foundation of China (Nos. 31502033 and 31472164), the Fundamental Research Funds for the Central Universities (No. KJQN201615), the Natural Science Foundation of Jiangsu Province (No. BK20130688), and the Priority Academic Program Development of Jiangsu Higher Education Institutions, China

(D. ORCID: Yuan-yuan XU, http://orcid.org/0000-0001-8069-9285

(C) Zhejiang University and Springer-Verlag Berlin Heidelberg 2016
}

closely related to Parkinson's, Alzheimer's, and cardiovascular diseases (Heafield et al., 1990; Rusin et al., 2004; Lin et al., 2008; Yang et al., 2011). Thus, a lot of effort has been put into quantifying the lowmolecule-weight biothiols in serum (Ni et al., 2015; Ghasemi et al., 2015). However, there has been very little work on the detection in cellular lysates including high-molecule-weight biothiols, although biothiol determination of total proteins in cell lysates is of great diagnostic significance.

Several methods based on chromatography, electrophoresis, and fluorescent technology for biothiol detection have been reported, especially nanomaterial-based methods much facilitated by the development of the underlying nanotechnology (Lee et al., 2008; Hong et al., 2009; Yi et al., 2009; Shiu et al., 2010; Liu et al., 2014; Zhang et al., 2014; Zhu et al., 2014). Each method has its own advantage; however, pretreatments of the materials or expensive equipments are often necessary to obtain a good performance. It is worth noting that employing metal nanomaterials in analytical strategies attracts more and more interest (Ran et al., 2013) and makes great 
progress in accurate and convenient biothiol detection Recently, a simple colorimetric method to assay biothiols in biosamples has been reported based on 3,3',5,5'-tetramethylbenzidine (TMB)-triggered silver (Ag) nanoparticles formation (Ni et al., 2015). In a typical test solution, the color of the solution changes from colorless to blue by mixing together TMB, a common chromogenic material, and silver ion $\left(\mathrm{Ag}^{+}\right)$ (Yang et al., 2008). When biothiols are present in the test system, biothiols would cause the reduction of oxidized TMB and at the same time could bind to $\mathrm{Ag}^{+}$, both of which suppress the TMB oxidized process, and thus the test solution remains colorless. It makes the detection procedure convenient. Clearly, the simpler the detection process, the wider the potential usage of the method.

We have carried out a series of experiments based on the above reported principles to achieve an optical method by optimizing the experimental conditions (Ni et al., 2015). Then the optical method was used to detect biothiols in bovine plasma and total proteins in different kinds of cell lines.

\section{Materials and methods}

\subsection{Chemicals and materials}

TMB and silver nitrate were purchased from Sigma-Aldrich (Shanghai, China). Twenty amino acids (including alanine (A), arginine (R), asparagine $(\mathrm{N})$, aspartic acid (D), cysteine (C), glutamine (Q), glutamic acid $(\mathrm{E})$, glycine $(\mathrm{G})$, histidine $(\mathrm{H})$, isoleucine $(\mathrm{I})$, leucine $(\mathrm{L})$, lysine $(\mathrm{K})$, methionine $(\mathrm{M})$, phenylalanine $(\mathrm{F})$, proline $(\mathrm{P})$, serine $(\mathrm{S})$, threonine $(\mathrm{T})$, tryptophan $(\mathrm{W})$, tyrosine $(\mathrm{Y})$, and valine $(\mathrm{V})$ ), GSH and $N$-ethylmaleimide (NEM) were from the Shanghai Sangon Biological Engineering \& Technology and Service Company (Shanghai, China). Fetal bovine serum (FBS) and Dulbecco's modified Eagle medium (DMEM) were bought from Sunshine Biotechnology Co., Ltd. (Nanjing, China). Ethanol, sodium acetate, and acetic acid were from the Nanjing Chemical Reagents Industry, China. All chemicals were used as supplied without further purification. TMB $(20 \mathrm{mmol} / \mathrm{L})$ was dissolved in ethanol. In addition, $1 \mathrm{mmol} / \mathrm{L}_{\mathrm{AgNO}_{3}}$ and $1 \mathrm{~mol} / \mathrm{L} \mathrm{NaAc}$ reaction buffer ( $\mathrm{pH}$ 4.0) were prepared by double-distilled water, which was purified with a Milli-Q purification system (Branstead, USA) to a specific resistance of 18.2 $\mathrm{M} \Omega \cdot \mathrm{cm}$ and stored at $4^{\circ} \mathrm{C}$.

\subsection{Preparation of biosamples}

Bovine blood samples were collected from a jugular catheter. Heparin was used as an anticoagulant and the bovine plasma was prepared by centrifugation at $3000 \mathrm{~g}$ at $4{ }^{\circ} \mathrm{C}$ for $10 \mathrm{~min}$ and stored at $-20{ }^{\circ} \mathrm{C}$.

The proteins were extracted from different cell lines by cell lysates. Cell lysates containing all proteins were obtained by the following procedure. All cell lines, including the hepatoma (Hepa), breast adenocarcinoma (MCF), breast cancer (4T1), the macrophage (RAW), the melanoma (F10), and the embryonic fibroblast cell line (3T3-H) were cultured in DMEM. Each cell line was first rinsed with phosphate buffered saline (PBS) three times. After incubation with $2 \mathrm{ml}$ trypsin at $37{ }^{\circ} \mathrm{C}$ for $1.5 \mathrm{~min}$, DMEM (FBS included) was added quickly and all solutions were collected by centrifugation at $1000 \mathrm{r} / \mathrm{min}$ for $5 \mathrm{~min}$. Then, a cell pellet was suspended with $1 \mathrm{ml}$ ice-cold PBS and centrifuged at $1000 \mathrm{r} / \mathrm{min}$ for $5 \mathrm{~min}$. After that, $100 \mu \mathrm{l}$ of cold lysis buffer was added to the cell pellet and placed on ice for $20 \mathrm{~min}$ and vortexed every $5 \mathrm{~min}$. Finally, by centrifuging at $12000 \mathrm{r} / \mathrm{min}$ for $5 \mathrm{~min}$, supernatant was collected and ready for use.

\subsection{Detection of biothiols}

The detection of biothiols was carried out at room temperature using $\mathrm{TMB}$ as an indicator in a $\mathrm{NaAc}$ buffer solution. In a typical run, biothiols (Cys or GSH) at different concentrations were first incubated with $\mathrm{AgNO}_{3}$ for a few seconds. Then TMB was added to the above mixture. The UV-Vis spectral measurements were carried out by monitoring the absorbance change after $1 \mathrm{~h}$ reaction at room temperature. Cys or GSH was replaced by bovine plasma or cell lysates in real sample detection.

\section{Results}

\subsection{Mechanism of the sensing system}

The proposed method for biothiol detection is comprised of $\mathrm{Ag}^{+}$and TMB. TMB can deoxidize silver ions, causing Ag nanoparticle formation, accompanied with the color changes from colorless to 


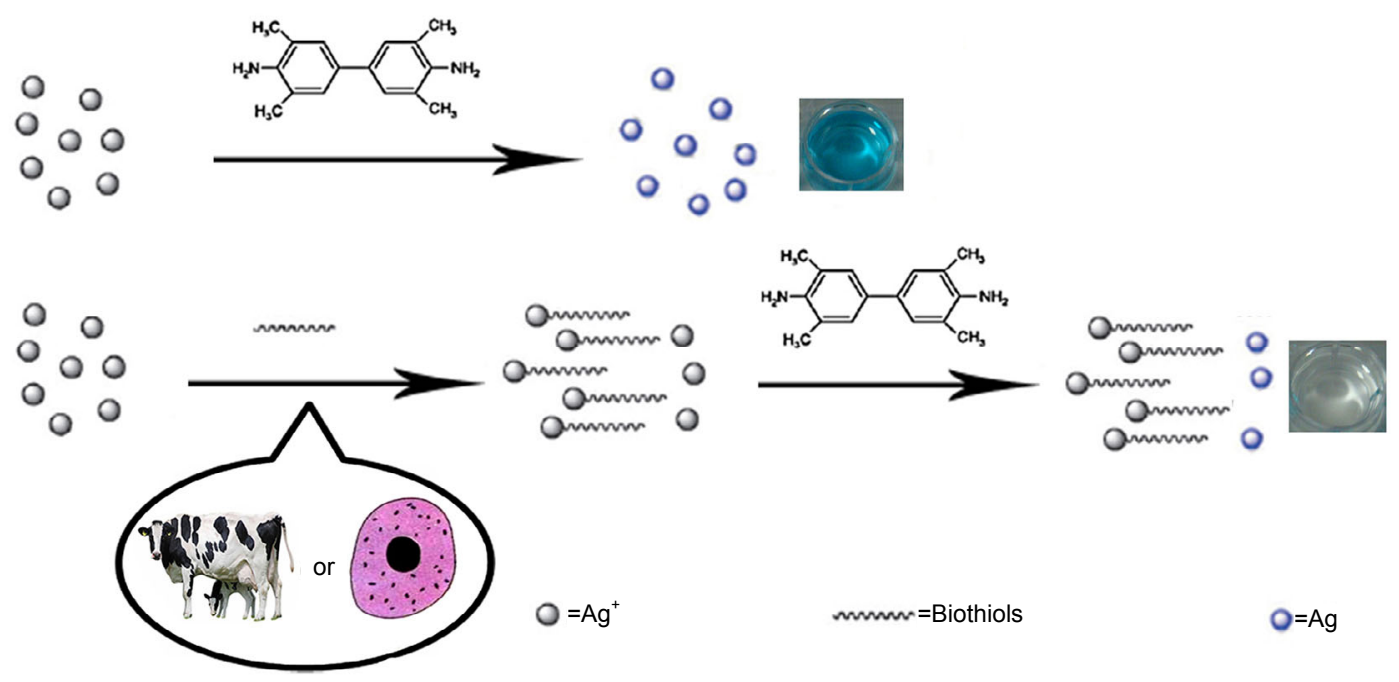

Fig. 1 Colorimetric assay of the detection of biothiols

blue (Yang et al., 2008). While biothiols can bind with $\mathrm{Ag}^{+}$first, this will further affect the oxidization of TMB and retain the colorlessness (Fig. 1). As the degree of color is closely negatively related with the quantity of biothiols in solution, a simple and sensitive assay for biothiol detection can be achieved.

\subsection{Feasibility and selectivity of biothiol detection}

The feasibility of this optical method is first identified by taking Cys as an example and experimental results from UV-Vis spectra and photographs are shown in Fig. 2. Without biothiols in solution, TMB is oxidized to $\mathrm{TMB}^{+}$by $\mathrm{Ag}^{+}$ion, which results in a significant peak at $656 \mathrm{~nm}$ in UV-Vis spectrum (curve A in Fig. 2). With the addition of biothiols, no peak at $656 \mathrm{~nm}$ can be detected (curve $\mathrm{C}$ in Fig. 2). An obvious difference can be observed in the presence and absence of biothiols. Furthermore, the effect of biothiols in this assay is further identified by NEM, a widely used thiol blocking agent (curve D in Fig. 2). There is almost no difference with curve A, which indicates that NEM-treated biothiols have nearly no influence on the oxide reaction between $\mathrm{Ag}^{+}$ions and TMB in this biothiols-containing system due to the blocking effect of NEM. The presence of NEM can impede the interaction between biothiols and $\mathrm{Ag}^{+}$ions, which will dispel the effect of biothiols on $\mathrm{Ag}^{+}$ions. As a result, the color of the solution changes from colorless to blue and the typical peak at $656 \mathrm{~nm}$ appears.

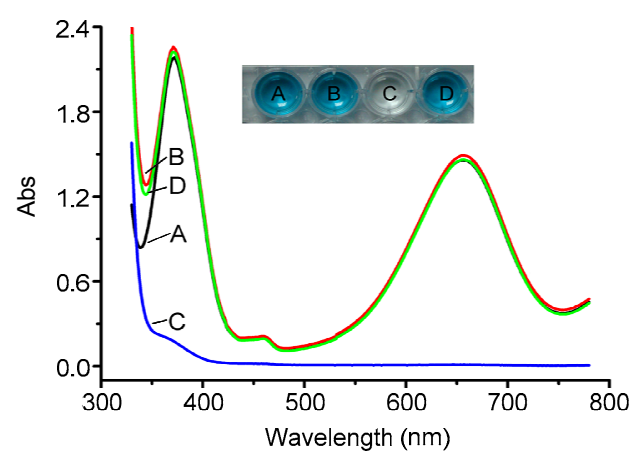

Fig. 2 UV-Vis spectra of different test solutions Curve $\mathrm{A}: \mathrm{Ag}^{+}$and TMB; Curve B: $\mathrm{Ag}^{+}, \mathrm{TMB}$ and NEM (thiol blocking agent); Curve C: $\mathrm{Ag}^{+}, \mathrm{TMB}$ and Cys; Curve D: $\mathrm{Ag}^{+}$, TMB, NEM and Cys. Inserted photographs of the test solutions contain: (A) $\mathrm{Ag}^{+}$and $\mathrm{TMB}$; (B) $\mathrm{Ag}^{+}$, $\mathrm{TMB}$ and NEM; (C) $\mathrm{Ag}^{+}, \mathrm{TMB}$ and Cys; (D) $\mathrm{Ag}^{+}, \mathrm{TMB}, \mathrm{NEM}$ and Cys

The selectivity of the method we proposed can be further confirmed. By testing 20 kinds of natural amino acids, it can be seen that only Cys can affect the oxide reaction between TMB and $\mathrm{Ag}^{+}$ions effectively. Thus, only the sample containing Cys remains colorless, while the other amino acid solutions all turn blue (Fig. 3a). The same results can be obtained by $\mathrm{UV}-\mathrm{Vis}$ spectra and the histogram of UV-Vis spectral responses of different amino acids is shown in Fig. 3b.

\subsection{Colorimetric detection of biothiols}

After demonstrating the feasibility and selectivity of the method, we go on to detect the concentration 
of biothiols. Two kinds of typical biothiols, Cys and $\mathrm{GSH}$, are used as examples. Cys, which plays important roles in cell metabolism, is first detected. Experimental results reveal that this method can detect Cys with good sensitivity. Each Cys in the test system can greatly affect the oxide reaction between TMB and $\mathrm{Ag}^{+}$ions. As shown in Fig. 4, the intensity of the characteristic peak at $656 \mathrm{~nm}$ decreases when the concentration of Cys increases. The absorbance peak almost disappears when the Cys concentration is more than $100 \mu \mathrm{mol} / \mathrm{L}$. By taking the concentration of Cys as the $x$-axis and the value of absorbance peak as the $y$-axis, the relationship between the absorbance at $656 \mathrm{~nm}$ deduct that at $753 \mathrm{~nm}\left(\mathrm{Abs}_{656-753 \mathrm{~nm}}\right)$ and Cys concentrations $\left(C_{\text {Cys }}\right.$, in $\left.\mu \mathrm{mol} / \mathrm{L}\right)$ is obtained (Fig. 5a). A linear relationship between $\mathrm{Abs}_{656-753 \mathrm{~nm}}$ and $C_{\mathrm{Cys}}$ within the range of $0.5-50.0 \mu \mathrm{mol} / \mathrm{L}$ is also gained (Fig. 5a, inset). The linear equation is $\mathrm{Abs}_{656-753 \mathrm{~nm}}=$ $-0.01544 C_{\text {Cys }}+0.91206\left(n=3 ; R^{2}=0.99983\right)$ with a detection limit at $0.11 \mu \mathrm{mol} / \mathrm{L}$. This method is not only suitable for detecting Cys but also biothiols in small peptides, such as GSH. As is shown in Fig. 5b, GSH can be detected in the linear range from 0.25 to $50.00 \mu \mathrm{mol} / \mathrm{L}$. The linear regression equation is $\mathrm{Abs}_{656-753 \mathrm{~nm}}=$ $-0.01924 C_{\mathrm{GSH}}+0.96297\left(n=3, R^{2}=0.99818\right)$ and the detection limit ( $3 \sigma$ ) is $0.09 \mu \mathrm{mol} / \mathrm{L}$, where $C_{\mathrm{GSH}}$ is the concentration of GSH $(\mu \mathrm{mol} / \mathrm{L})$.

\subsection{Biothiols in real samples}

It has been widely accepted that the quantity of biothiols in vivo is highly related to certain diseases, so determination of biothiols in biosamples is of great diagnostic significance. To make sure of more explicit applications of our method in practical samples, we tested the biothiols of total proteins in bovine plasma and different cell lines. Bovine blood samples were collected from a jugular catheter and the bovine plasma was prepared by centrifugation. According to the sensor, the quantity of biothiols in bovine plasma

(a)

(b)

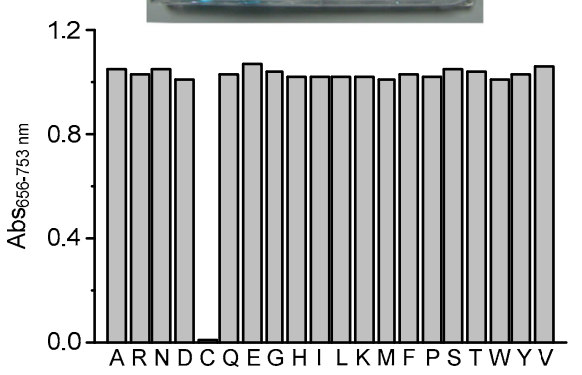

Fig. 3 Photographs (a) and histogram of UV-Vis spectra (b) for different amino acids

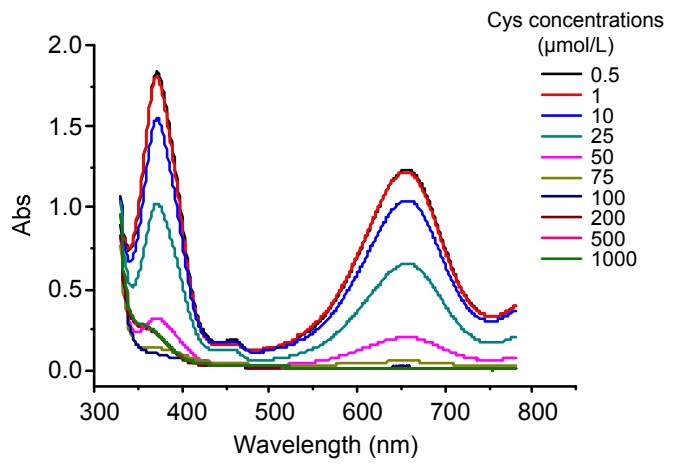

Fig. 4 UV-Vis spectra of mixed solution in the presence of different concentrations of Cys
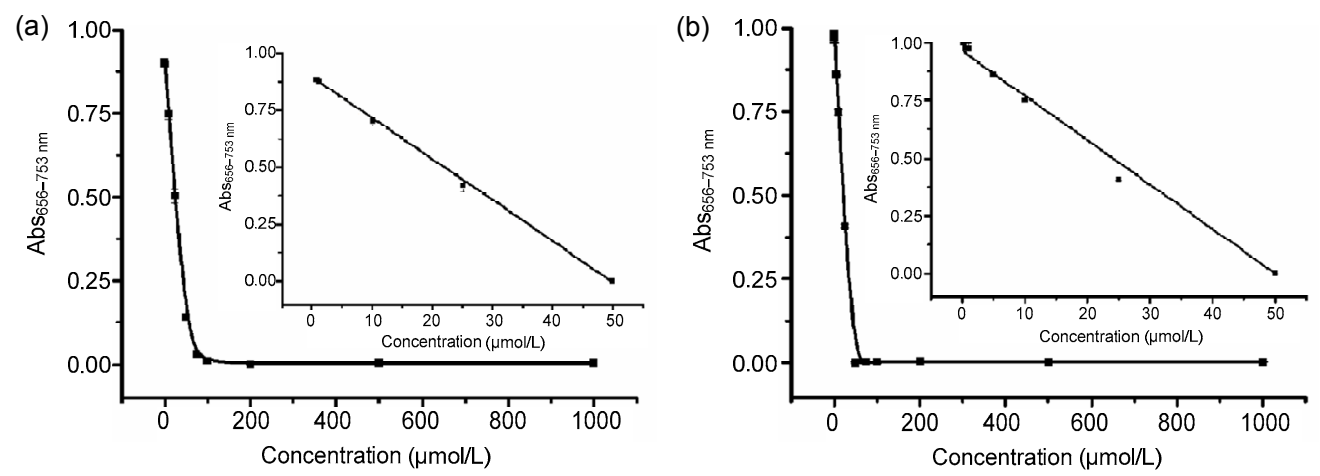

Fig. 5 Calibration curves of Cys (a) and GSH (b) with different concentrations

The inset indicates that the values of $\mathrm{Abs}_{656-753 \mathrm{~nm}}$ versus the Cys (a) or GSH (b) concentrations are linear over the range of $0.5-50.0 \mu \mathrm{mol} / \mathrm{L}$. The data are presented as mean \pm standard deviation (SD) from three independent tests 
Table 1 Determination of biothiols in bovine plasma

\begin{tabular}{cccccc}
\hline No. & Determined biothiol $(\mu \mathrm{mol} / \mathrm{L})$ & Added Cys $(\mu \mathrm{mol} / \mathrm{L})$ & Found Cys $(\mu \mathrm{mol} / \mathrm{L})$ & Recovery $(\%)$ & RSD $(\%)$ \\
\hline 1 & 486 & 1250 & 1743 & 100.56 & 0.794 \\
2 & 486 & 2500 & 2988 & 100.08 & 2.101 \\
\hline
\end{tabular}

RSD: relative standard deviation. The data are determined after three parallel experiments

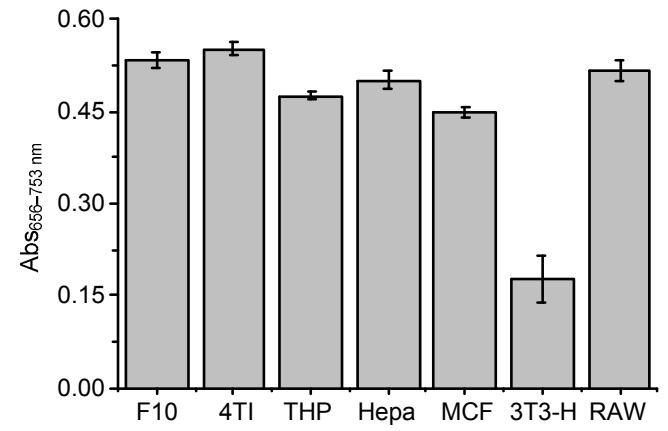

Fig. 6 Histogram of UV-Vis spectral responses to 7 kinds of cell lysates

The data are presented as mean \pm SD from three independent tests

was $486 \mu \mathrm{mol} / \mathrm{L}$ (Table 1). We added different quantities of Cys into bovine plasma and tested it again. After three parallel experiments $(n=3)$, it can be seen that good recoveries can be obtained with relative standard deviation less than $2.5 \%$, which means that this method can detect biothiols in complex biosamples effectively. We then successively evaluated the biothiol quantity of total proteins in different cell lines (Fig. 6). After cell disruption and adjusting the quantity of total protein equal to $1 \mathrm{mg} / \mathrm{ml}$, the results revealed the quantities of biothiols in different cell lines. It can be seen that the contents of biothiols in 3T3-H cells are at least double that in the other six kinds of cell lines.

\section{Conclusions}

Following on from the previously reported work, not only the quantity of biothiols in bovine plasma is identified, but also biothiols including high-moleculeweight biothiols in different cell lysates are detected. By comparing biothiols of total proteins in different cell lines, it was found that the percentage of biothiols in $3 \mathrm{~T} 3-\mathrm{H}$ cells is significantly higher than those in other cell lines, which offers great value in the related embryonic fibroblast cell study.

\section{Contributors}

Jin-feng MIAO and Yuan-yuan XU conceived the project and designed the experiments. Yuan-yuan XU and Yang-yang SUN performed the experiments. Yu-juan ZHANG and Chenhe LU prepared figures and wrote the manuscript.

\section{Compliance with ethics guidelines}

Yuan-yuan XU, Yang-yang SUN, Yu-juan ZHANG, Chen-he LU, and Jin-feng MIAO declare that they have no conflict of interest.

All institutional and national guidelines for the care and use of laboratory animals were followed. The animal care and use protocol employed is approved by the Institutional Animal Care and Use Committee of Nanjing Agricultural University and implemented in accordance with the Regulations for the Administration of Affairs Concerning Experimental Animals (China, 1988) and the Standards for the Administration of Experimental Practices (Jiangsu, China, 2008).

\section{References}

Duan, L., Xu, Y., Qian, X., et al., 2008. Highly selective fluorescent chemosensor with red shift for cysteine in buffer solution and its bioimage: symmetrical naphthalimide aldehyde. Tetrahedron Lett., 49(47):6624-6627. http://dx.doi.org/10.1016/j.tetlet.2008.09.021

Ghasemi, F., Hormozi-Nezhad, M.R., Mahmoudi, M., 2015. A colorimetric sensor array for detection and discrimination of biothiols based on aggregation of gold nanoparticles. Anal. Chim. Acta, 882:58-67. http://dx.doi.org/10.1016/j.aca.2015.04.011

Heafield, M.T., Fearn, S., Steventon, G.B., et al., 1990. Plasma cysteine and sulphate levels in patients with motor neurone, Parkinson's and Alzheimer's disease. Neurosci. Lett., 110(1-2):216-220. http://dx.doi.org/10.1016/0304-3940(90)90814-P

Hong, V., Kislukhin, A.A., Finn, M., 2009. Thiol-selective fluorogenic probes for labeling and release. J. Am. Chem. Soc., 131(29): $9986-9994$. http://dx.doi.org/10.1021/ja809345d

Lee, K.S., Kim, T.K., Lee, J.H., et al., 2008. Fluorescence turn-on probe for homocysteine and cysteine in water. Chem. Commun., 46:6173-6175. http://dx.doi.org/10.1039/B814581D

Lin, W., Long, L., Yuan, L., et al., 2008. A ratiometric fluorescent probe for cysteine and homocysteine displaying a large emission shift. Org. Lett., 10(24):5577-5580. http://dx.doi.org/10.1021/ol802436j 
Liu, J., Sun, Y.Q., Huo, Y., et al., 2014. Simultaneous fluorescence sensing of Cys and GSH from different emission channels. J. Am. Chem. Soc., 136(2):574-577. http://dx.doi.org/10.1021/ja409578w

Ni, P., Sun, Y., Dai, H., et al., 2015. Highly sensitive and selective colorimetric detection of glutathione based on $\mathrm{Ag}[\mathrm{I}]$ ion-3,3',5,5'-tetramethylbenzidine (TMB). Biosens. Bioelectron., 63:47-52. http://dx.doi.org/10.1016/j.bios.2014.07.021

Ran, X., Sun, H., Pu, F., et al., 2013. Ag nanoparticle-decorated graphene quantum dots for label-free, rapid and sensitive detection of $\mathrm{Ag}^{+}$and biothiols. Chem. Commun., 49(11): 1079-1081. http://dx.doi.org/10.1039/C2CC38403E

Reddie, K.G., Carroll, K.S., 2008. Expanding the functional diversity of proteins through cysteine oxidation. Curr. Opin. Chem. Biol., 12(6):746-754. http://dx.doi.org/10.1016/j.cbpa.2008.07.028

Rusin, O., St. Luce, N.N., Agbaria, R.A., et al., 2004. Visual detection of cysteine and homocysteine. J. Am. Chem. Soc., 126(2):438-439. http://dx.doi.org/10.1021/ja036297t

Shiu, H.Y., Chong, H.C., Leung, Y.C., et al., 2010. A highly selective FRET-based fluorescent probe for detection of cysteine and homocysteine. Chemistry, 16(11):3308-3313. http://dx.doi.org/10.1002/chem.200903121

Townsend, D.M., Tew, K.D., Tapiero, H., 2003. The importance of glutathione in human disease. Biomed. Pharmacother., 57(3):145-155. http://dx.doi.org/10.1016/S0753-3322(03)00043-X

Wang, W., Rusin, O., Xu, X., et al., 2005. Detection of homocysteine and cysteine. J. Am. Chem. Soc., 127(45): 15949-15958. http://dx.doi.org/10.1021/ja054962n

Weerapana, E., Wang, C., Simon, G.M., et al., 2010. Quantitative reactivity profiling predicts functional cysteines in proteomes. Nature, 468(7325):790-795. http://dx.doi.org/10.1038/nature09472

Yang, J., Wang, H., Zhang, H., 2008. One-pot synthesis of silver nanoplates and charge-transfer complex nanofibers. J. Phys. Chem. C, 112(34):13065-13069. http://dx.doi.org/10.1021/jp802604d

Yang, X., Guo, Y., Strongin, R.M., 2011. Conjugate addition/ cyclization sequence enables selective and simultaneous fluorescence detection of cysteine and homocysteine. Angew. Chem. Int. Ed., 50(45):10690-10693. http://dx.doi.org/10.1002/anie.201103759

Yang, X., Guo, Y., Strongin, R.M., 2012. A seminaphthofluorescein-based fluorescent chemodosimeter for the highly selective detection of cysteine. Org. Biomol. Chem., 10(14): 2739-2741. http://dx.doi.org/10.1039/C2OB25178G

Yi, L., Li, H., Sun, L., et al., 2009. A highly sensitive fluorescence probe for fast thiol-quantification assay of glutathione reductase. Angew. Chem. Int. Ed., 48(22):40344037. http://dx.doi.org/10.1002/anie.200805693

Zhang, L., Lu, B., Lu, C., et al., 2014. Determination of cysteine, homocysteine, cystine, and homocystine in biological fluids by HPLC using fluorosurfactant-capped gold nanoparticles as postcolumn colorimetric reagents. J. Sep. Sci., 37(1-2):30-36. http://dx.doi.org/10.1002/jssc.201300998

Zhu, B., Guo, B., Zhao, Y., et al., 2014. A highly sensitive ratiometric fluorescent probe with a large emission shift for imaging endogenous cysteine in living cells. Biosens. Bioelectron., 55:72-75. http://dx.doi.org/10.1016/j.bios.2013.11.068

\section{中文概要}

题 目: 生物疏化物的可视化检测

目 的: 通过简单可靠的可视化检测方法评估牛血清及各 细胞系中生物颈化物的含量。

创新点: 基于银纳米颗粒形成的比色变化过程对牛血清及 细胞中生物颈化物进行了检测。

方 法: 将 6 组不同的细胞系培养后进行裂解, 其裂解产 物分别与 $3,3^{\prime}, 5,5^{\prime}$-四甲基联苯胺 (TMB) 和硝酸 银 $\left(\mathrm{AgNO}_{3}\right)$ 的混合液室温捊育后, 用紫外可见 分光光度计测量细胞中生物颈化物的含量。

结 论: 通过不同细胞系中生物巯化物含量的比对, 证实 胚胎成纤维细胞中生物颈化物的含量明显高于 其他细胞。

关键词: 生物颈化物; 可视检测; 牛血清; 细胞系 